\title{
A SIMULATION MODEL FOR INTENSIVE PIGLET PRODUCTION SYSTEMS
}

\author{
Lluís M. Plà-Aragonès \\ Virginia Flores Marias \\ Sara V. Rodríguez-Sánchez \\ Dept. of Mathematics \\ 73, Jaume II, University of Lleida \\ 25001 Lleida, SPAIN
}

\begin{abstract}
A simulation model representing the dynamics of a sow farm is presented in contrast with other approaches. To highlight relevant aspects of the model a real application for planning piglet production is considered. The main contribution of the model is that sow herd management is based on batches of sows being in the same reproductive state, as actually is done in practice. This features allow to measure the discrepancy with other approaches and comparing different reproductive management strategies in a more realistic way than by using other quantitative methods. Furthermore, the implementation in Extend allows potential users to perform efficiently different kinds of analyses tracking variables of their own interest.
\end{abstract}

\section{INTRODUCTION}

Many software programs for pig farm management based on different herd management models have been developed and introduced for on-farm use, but they have not been widely used (Kamp 1999, Gelb 1999). It is recognized there are farm management areas where decision tools are less developed, especially when tactical and strategic decisions are involved. This is a surprising fact, taking into account that strategic decisions are important for farm viability. Maybe the simplicity required in getting the big decisions right and making correctly the major tactical adjustments (Pannell et al. 2000) is the reason. However, the availability of better tools to compare alternative management strategies is always needed and simulation models can play an important role on that.

Classical livestock models for sow farms are mainly based on static (or stationary) and equivalent deterministic models. The activity developed in a farm can change over time due to technological advances or management practices. Behavior of animals and responses to farmer's actions are variable depending on many factors controllable or not and not always present like temperature, diseases, feeding levels or quality of concentrates. Economic activity within intensive livestock models turn around the representation of the reproduction process in a breading herd. Then in a sow farm, the herd is compounded by number of sows in different reproductive stages. Usually, operations in sow farms are classified according to three main reproductive stages: breeding, gestation and lactation, so average time intervals associated to them are essential for planning housing facilities and keeping a constant workload day by day during the week (Wittemore 1998). This implies that standard operations like moving animals from one facility to another, inseminations, regular medical cares after, weaning of piglets, heat detection, pregnancy test, culling of sows, reception of gilts and delivery of piglets among others are organized in a weekly basis and in a rational way. Any disruption in this plans may cause serious troubles to the farmer and certain decline of revenues.

Given the importance of the capacity of farm facilities, there exist simulation approaches focused in housing facilities, for instance, Singh (1986) proposed a simulation model to select the optimum capacity of swine production facilities considering batch management. Later on, Lippus et al. (1996) adapted a previous Markov chain model, developed by Jalvingh et al. (1992), to support strategic planning for housing facilities for sows. They considered immediate replacement of sows, constant herd size and weekly management. Later Plà (2005) presented a model to solve the housing facilities design comparing different model approaches. However, previous simulation models did not represent usual management practices in detail. Most common management practices concerning reproduction and replacement of animals can be hardly took into account in structured mathematical models, for instance, the weaning of piglets at a fixed date (every Wednesday) sows grouped in batches or gilts purchased in a minimum number. Thus, in this work a simulation mod- 
el for sow herd dynamics representing usual management practices implemented in intensive sow farms is developed and an application for planning piglet production based on it is introduced.

\section{THE PIGLET PRODUCTION MODEL}

Few years ago, pig production was held in just one farm, the so called farrowing-to-finish farms. Nowadays, specialization and disease problems have lead to a different production framework in Spain and other countries leading pig production. Farms are organized in what can be called a pork chain. Then it can be distinguished sow farms producing piglets, rearing farms and fattening farms. The flow of production along the chain is important because in the last stage of the chain the all-in all-out policy is usually adopted and therefore production at the first stage of the chain have to feed the room availability in a farm at a specific time window. This is of interest for firms taking part in the pork chain and needing to have a stable production over time. Hence, the essence of this system relies on an regular production of piglets over time.

In this context, the proposed simulation model represents a piglet production system. A requirement of the system is that piglets have to be produced regularly. Piglets are produced in a sow herd. This is characterized by a herd of sows in a continuous process of reproduction. The farm is owned by a firm or by a farmer integrated in a bigger commercial structure, but with the commitment of producing piglets to be delivered regularly to another farm. Hence, piglets are the commercial product, which after weaning are sold to rearing-fattening farms. This specialization gives additional efficiency gains as Rowland et al. (1998) pointed out and it is widely extended within the Spanish swine industry.

Daily operations in a sow farm are weekly scheduled in commercial farms. This way work force is more efficient. As result, sows are grouped in batches allowing this rationalization of tasks. For instance, matings are performed on Tuesday and Wednesday, weaning of piglets is done on Thursday and Friday and heat control and gestation detection on Monday. These planning of activities rarely are took into account by livestock models and even they represent a lot of complexities for a structured mathematical modeling approach. In addition, the impact of changes in reproductive management or the comparison of management alternatives should consider this aspects of extreme practical importance.

\section{MODEL IMPLEMENTATION}

The simulation model was implemented in Extend, an interactive simulation tool (Krahl 2003).
The Extend simulation environment provides the tools for all levels of modelers to create accurate, credible, and usable models in an efficient way. Extend was chosen because it facilitates every phase of the simulation project, from creating, verifying, and validating the model, to the construction of a user interface which allows others to analyze the system. An additional advantage for developers is the Extend's built-in, compiled language, ModL, to create reusable modeling components. All of this is done within a single, self-contained software program that does not require external interfaces, compilers, or code generators.

Model structure is presented in Figure 1. Main elements of the model are: the block of general parameters and the block representing the farm All of them are tailored made blocks that can be complemented with standard ones as the Plotter I/O or the File Out blocks.

The block of general parameters and this of the farm are hierarchical blocks, that is, they are built from other blocks. For instance, the block of parameters contains six blocks each one representing a set of parameters affecting herd dynamics: casualties, conception, abortion, lactation management, economic issues and technical issues. This block opened in a window is shown on the left of Figure 1 while the block highlighted behind is the aspect of this hierarchical block in the standard form (i.e. closed).

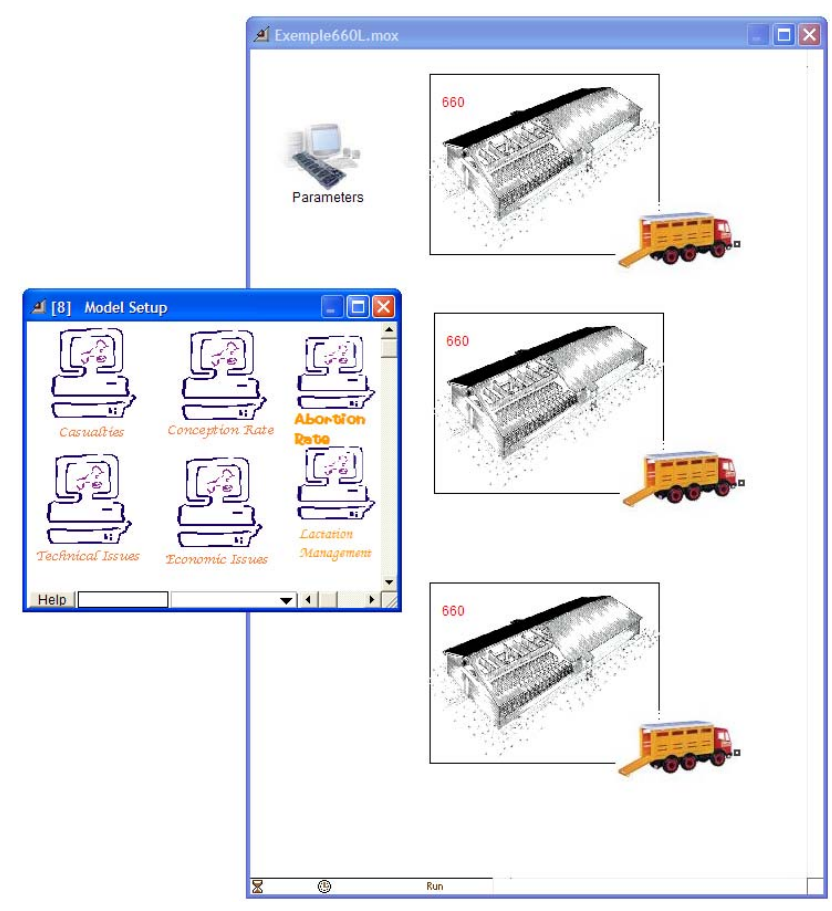

Figure 1: General Model Structure

Each of these six blocks can be opened and they show specific parameters of the model. Values of these parameters are defined by default but can be modified by 
users representing particular reproductive and replacement management strategies implemented by the farmer.

The block of the farm is associated with an icon representing a drawn farm. Three of them can be seen on Figure 1. The farm block is a hierarchical block and itself contains blocks representing each individual sows o a group of sows in a batch. As all these elements are hold in a library, the farm size is customizable. The basic component of the farm is the crate where each animal that can be housed in.

Hierarchical blocs are elements that can be added to the model in number equal or greater to one. For instance, Figure 1 shows how a hypothetical company of three farms could be represented. Each farm can be customized in terms of number of sows and individual parameters ruling the reproduction process.

In fact this model is a refinement of that presented in Plà (2005). Main differences are concerning the new set of parameters included to better represent a wide range of management alternatives. These alternatives allow to consider batch management of sows, weekly operations on the far and introduce capacity constraints in some facilities. This way, practical problems in the real implementation of management strategies are better detected and analyzed.

\section{VERIFICATION}

For verification purpose the model was compared with analytical results (Kleijnen, 1995). The simulation model was not run with all possible parameters, only those compatible with the analytical model were set. The main outcome used in the verification was the herd steady state distribution. Herd distribution is selected because is the main variable affecting farm outputs as Jalvingh et al. (1992) noticed. Analytical results for stationary herd distribution were derived when modeling the herd dynamics as a Markov Chain.

Verification process was automatized by developing a specific block. This block monitored and stored the sow herd composition at any time beyond the warm-u period. Run length was of 10.000 days and the last 1.000 were used to calculate average herd distribution and compared with analytical results. Chi-square distance was used to measure the proximity of both results and always the model reproduced the analytical results with enough precision (results not shown).

\section{PRELIMINAR RESULTS AND INTENDED USE}

In order to assess the benefits of the simulation model and to measure possible advantages of it in planning piglet production, a comparison was established between the model ignoring random of variables and correlations (i.e. adopting expectations for random parameters) and the same simulation model but taken into account full capabilities of the model to reflect real systems (i.e. generating random values for each random variable considered). This comparison may serve to value the goodness of the simulation model face to previous methodologies based on more deterministic proposals. Thus, a group of parameters satisfying the needs of both runs was set. These parameters represent the management policy related to facilities and production level that the farmer wants to implement or achieve. The data on biological production parameters used in this paper were inspired from computerized records of Bd-Porc databank (2000), the main Spanish pig information system and from literature. All parameters used in this case example and described below are presented in Appendix A.

In the first comparison results a run of 10000 days was performed twice. The only difference was the presence or not of some random elements. The observations reported the last 2000 days (shown in Table 1) were considered to make a comparison of a two-sample t-test of means. No significance difference was found. This results reflect the unpredictable outcomes of animals in the random case leading to a slight decline in the number of piglets against expected values driving the deterministic case. However this trend is not significant from the t-test performed.

Table 1: Total piglet production from $\mathrm{t}=8000$ to $\mathrm{T}=10000$

\begin{tabular}{|c|c|c|c|c|}
\hline $\mathrm{N}$ & Mean & StDev & SE Mean & Elements \\
\hline 96 & 648.0 & 97.2 & 9.9 & Random \\
\hline 96 & 654.2 & 87.2 & 8.9 & Not Rand \\
\hline
\end{tabular}

Variables of interest can be displayed by using a Plot Block present in the EXTEND library. For instance, Figure 2 shows the plot of piglet production over time when variability was not considered. This outcomes can be discussed easily with experts.

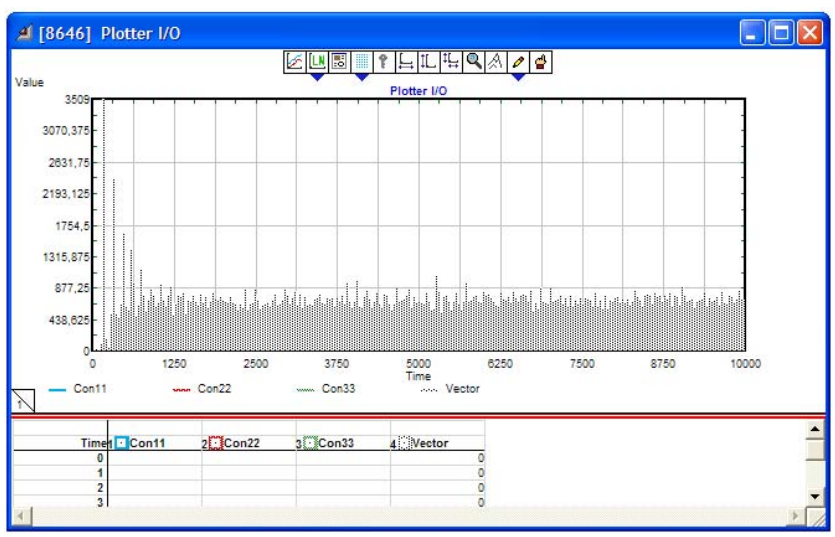

Figure 2: Piglet production over time 
Finally, a comparison to value the effect of batch management is performed. This instance is more complex that the one shown before. Furthermore, policy of culling and purchasing animals have to be represented. That is, only groups of 5 or more are send to the slaughterhouse or purchased at a time. When batches of animals are not considered then this management strategy is called continuous management. A continuous management of animals is expected to take advantage of facilities allowing a near full occupation, but this is practically unrealistic in commercial herds. A batch management implies a lower occupancy of facilities but a more rational scheduling of farmer's activities. Moreover, disease risks can not be neglected in this case. Drying and cleaning period is harder to implement when a continuous management is ruled.

Table 2: Total piglet production under batch management

\begin{tabular}{|c|c|c|c|c|}
\hline N & Mean & StDev & SE Mean & Management \\
\hline 467 & 665 & 272 & 13 & Batch \\
\hline 467 & 649 & 189 & 8,8 & Continuous \\
\hline
\end{tabular}

The observations of these simulations were collected, and compared by a two-sample t-test of means. No significance difference was found. However a greater variability is observed when batch management is performed. These preliminary results may explain why batch management does not affect strongly in the formulation of mathematical models representing pig production. Despite these results, scheduling of daily tasks on farm and practical implementation of several management strategies may be unfeasible.

\section{CONCLUSIONS}

The simulation model described here represents a practical approach for planning piglet production under different farm management strategies. It is more flexible and accurate than deterministic or stationary approaches, essentially because it better captures the dynamics of the sow production and reproduction process. The use of a visual simulation tool like EXTEND is essential to interact with specialist during the development of the model. Moreover, different advantages are drawn respect to previously published models for the same purpose like batch management. The simulation model considers variations in sow performance and can explore alternative management. We have shown how feasible solutions are unpractical because they go against rational work of farmers scheduled in a weakly basis and how important is this constraint to be taken into account in future developments.

\section{ACKNOWLEDGMENTS}

This work has been done by funding of Spanish Ministry of Science and Education by means of the Spanish Research Program, project code: MTM2005-09362-C03-02. Sara V. Rodriguez acknowledge to the Department of Universities and Information Society (autonomous government of Catalonia) the grant received during the development of this work.

\section{A PARAMETERS OF THE SIMULATION MODEL}

The parameters enumerated here are classified in randomtime intervals (Table 5), time intervals under farmer's control (Table 6), transition probabilities (Table 7) and management requirements. Distribution of random time intervals shown in Table 5 are extracted from the exploratory analysis introduced in Marin et al. (2005).

Table 5: Random Time Intervals

\begin{tabular}{|l|c|}
\hline Time interval & $\begin{array}{l}\text { Distribution } \\
\text { in days }\end{array}$ \\
\hline Interval to first mating & $\Gamma(7,0.5)$ \\
\hline Interval between matings & $\mathrm{N}(21,3)$ \\
\hline Gestation & $\mathrm{N}(115,2)$ \\
\hline Abortion & weib $(5,80)$ \\
\hline Interval mating to culling & $\mathrm{N}(28,3)$ \\
\hline Interval otherwise to culling & $\mathrm{N}(7,3)$ \\
\hline
\end{tabular}

Table 6: Time Intervals under farmer's control

\begin{tabular}{|l|c|}
\hline Time interval & $\begin{array}{l}\text { Distribution } \\
\text { in days }\end{array}$ \\
\hline Lactation & 21 \\
\hline $\begin{array}{l}\text { Time interval to be moved to ges- } \\
\text { tation facility after mating }\end{array}$ & 28 \\
\hline $\begin{array}{l}\text { Time interval to be moved to lac- } \\
\text { tation facility before farrowing }\end{array}$ & 7 \\
\hline Drying period after weaning & 7 \\
\hline
\end{tabular}

Table 7: Transition Probabilities

\begin{tabular}{|l|c|}
\hline & Probability \\
\hline Conception & 0.80 \\
\hline Abortion & 0.02 \\
\hline Mortality & 0.08 \\
\hline Casualties & 0.12 \\
\hline
\end{tabular}

Decisions involved in different reproductive management strategies requirements are considered through 
parameters as: size of batches of sows or the delay between batches, the maximum lifespan (fixed at 11 reproductive cycles), the maximum number of mating per reproductive cycle (two matings maximum), the number of abortions permitted (only two abortions per sow), the maximum litter size to be fostered (four piglets), the minimum productivity of sows to be culled (four piglets). Lactation management involves decision variables affecting weanings like when piglets are weaned (scheduled every three weeks), the minimum age of piglets for being weaned (two weeks of lactation). The farm size was set to 660 sows. For verification parameters were not affected by reproductive cycle.

\section{REFERENCES}

Brent, G. 1986. Housing the pig. Farming Press.

Gelb, E.M. 1999. Adoption of IT by farmers- Does reality reflect the potential benefit?. In Proceedings Second European Conference EFITA, 433-441. Bonn, Germany.

Jalvingh, A.W., A.A. Dijkhuizen and J.A.M. van Arendonk. 1992. Dynamic probabilistic modelling of reproduction and management in sow herds. General aspects and model description. Agricultural Systems 39: 133-152.

Kamp, J.A.L.M. 1999. Knowledge based systems: from research to practical application. Pitfalls and critical success factors. Computers and Electronics in Agriculture 22: 243-250.

Kleijnen, J.H.P. 1995. Verification and validation of simulation models. European Journal of Operational Research 82: 145-162.

Krahl, D. 2003. Extend: an interactive simulation tool. In Proceedings of the 2003 Winter Simulation Conference, ed. S. Chick, P. J. Sánchez, D. Ferrin, and D. J. Morrice, 198-196. IEEE, Piscataway, NJ.

Lippus, A.C., A.W. Jalvingh, J.H.M. Metz and R.B.M. Huirne. 1996. A dynamic probabilistic model for planning housing facilities for sows. Transactions of the ASAE 39: 1215-1223.

Marín, J.M., L.M. Plà and D. Ríos. 2005. Inference for some stochastic process models related with sow farm management. Journal of Applied Statistics. In Press.

Panell, D.J., B. Malcom and R.S. Kingwell. 2000. Are we risking too much? Perspectives on risk in farm modelling. Agricultural Economics 23: 69-78.

Plà, L.M., D. Babot and J. Pomar. 2004. A mathematical model for designing and sizing sow farms. International Transactions in Operational Research. 11: 485-494.

Plà-Aragonès, L.M. 2005. A stochastic model for planning swine facilities. In Proceedings of the 2005 Win- ter Simulation Conference, ed. Kuhl, Steiger, Armstrong and Joines, 2378-2384. Orlando, Fl.

Rowland, W.W., M.R. Langemeier, B.W. Schurle and A.M. Featherstone. 1998. A nonparametric efficiency analysis for a sample of Kansas swine operations. Journal of Agricultural and Applied Economics. 30:189-199.

Singh, D. 1986. Simulation-aided capacity selection of confinement facilities for swine production. Transactions of the ASAE 29, 807-815.

Wittemore, C. 1998. The science and practice of pig production. Oxford. Blackwell Science Ltd.

\section{AUTHOR BIOGRAPHIES}

LLUIS M. PLA-ARAGONES is an associate professor in the Department of Mathematics at University of Lleida (UdL) and a Senior Researcher in the Area de Producción Animal at the UdL-IRTA Center. His research interests include operational research methods applied in agriculture and forest management, with special reference to simulation, dynamic programming, planning, Markov decision processes and production planning. Coordinator of the EURO-Working group: Operational Research in Agriculture and Forest management. $\mathrm{He}$ is a member of INFORMS and EURO. His e-mail address is $<$ Lmpla@matematica.udl.cat $>$ and his Web address is $<$ www.udl.es/usuaris/d4089492/>.

SARA V. RODRIGUEZ-SANCHEZ is a PhD student of the Department of Mathematics at University of Lleida (UdL). Her research interests include operational research methods applied in agriculture and forest management, with special reference to simulation, dynamic programming, planning, Markov decision processes and production planning. She is a member of INFORMS and EURO.

VIRGINIA FLORES-MARIAS is a PhD student of the Department of Mathematics at University of Lleida (UdL). Her research interests include operational research methods applied in agriculture and forest management, with special reference to simulation, dynamic programming, planning, Markov decision processes and production planning. She is a member of EURO. 